\title{
Running safety assessment of a train traversing a three-tower cable-stayed bridge under spatially varying ground motion
}

\author{
Wei Gong ${ }^{1} \cdot$ Zhihui Zhu $^{1,2}$ (1) $\cdot$ Yu Liu ${ }^{1} \cdot$ Ruitao Liu $^{1} \cdot$ Yongjiu Tang $^{1} \cdot$ \\ Lizhong Jiang ${ }^{1,2}$
}

Received: 13 January 2020/Revised: 2 March 2020/ Accepted: 4 March 2020/Published online: 31 March 2020

(C) The Author(s) 2020

\begin{abstract}
To explore the influence of spatially varying ground motion on the dynamic behavior of a train passing through a three-tower cable-stayed bridge, a 3D traintrack-bridge coupled model is established for accurately simulating the train-bridge interaction under earthquake excitation, which is made up of a vehicle model built by multi-body dynamics, a track-bridge finite element model, and a 3D rolling wheel-rail contact model. A conditional simulation method, which takes into consideration the wave passage effect, incoherence effect, and site-response effect, is adopted to simulate the spatially varying ground motion under different soil conditions. The multi-time-step method previously proposed by the authors is also adopted to improve computational efficiency. The dynamic responses of the train running on a three-tower cablestayed bridge are calculated with differing earthquake excitations and train speeds. The results indicate that (1) the earthquake excitation significantly increases the responses of the train-bridge system, but at a design speed, all the running safety indices meet the code requirements;

(2) the incoherence and site-response effects should also be considered in the seismic analysis for long-span bridges though there is no fixed pattern for determining their influences; (3) different train speeds that vary the vibration characteristics of the train-bridge system affect the vibration frequencies of the car body and bridge.
\end{abstract}

Zhihui Zhu

zzhh0703@163.com

1 Shool of Civil Engineering, Central South University, Changsha 410075, China

2 National Engineering Laboratory for High-Speed Railway Construction, Changsha 410075, China
Keywords Earthquake $\cdot$ Spatially varying ground motion . Long-span bridges - Nonlinear wheel-rail contact . Running safety

\section{Introduction}

High-speed railways (HSR) have played an increasingly important role in solving traffic problems in many countries [1, 2], especially for China, which has the largest population in the world. As bridges provide smooth and stable line conditions for high-speed trains in China, they contribute a significant portion of HSR. Thus, when an earthquake occurs, it is quite possible that trains are running on bridges. Therefore, the performance evaluation of a train traversing bridges under earthquake excitation has been an issue of concern for decades in the development of HSR [3].

Long-span bridges, which are capable of crossing large valleys and rivers and possess aesthetic values, have been increasingly used with the development of construction technology and building materials $[4,5]$. In the seismic analysis of long-span bridges, it is reasonable and necessary to consider the variation of the earthquake excitations under different supports, due to long distance and soil condition change between supports [6, 7]. A considerable number of studies have explored the responses of long-span bridges under multi-support seismic excitations [6-10], all indicating that the spatial variability effects of earthquake waves should be taken into consideration in the seismic analysis of long-span bridges. However, few studies have investigated the running safety of a train traversing a long- 
span bridge under spatially varying ground motions. $\mathrm{Mu}$ [11] investigated the responses of a train traversing a cablestayed bridge under uniform vertical seismic excitations and compared the responses of the train-bridge coupled system at different train speeds and seismic intensities. Zhang et al. [12] proposed a numerical solution to simulate the dynamic responses of a train traversing a cable-stayed bridge under traveling seismic waves. However, only the wave passage effect of the ground motion was considered in that study. Frýba [13] dealt with the responses of a suspended bridge subjected to moving loads and earthquake excitation and investigated the influence of different arrival times of an earthquake. Xia et al. [14] studied the influence of the propagation velocities of earthquake waves on the dynamic responses of the train-bridge system and concluded that although no fixed pattern could be observed for the influence of the propagation velocity, the seismic wave passage effect should be considered in evaluating the train running safety. Zeng [15] used the pseudo-excitation method to investigate the random vibrations when a train traversed a continuous girder bridge and was subjected to traveling seismic waves, pointing out that the wave passage effect could increase or decrease the responses of the trainbridge system. Nonetheless, the variation of the earthquake waves at different locations involves not only the different arrival times but also the amplitude and frequency changes due to soil conditions. Both should also be considered in the seismic analysis of the train-bridge system.

Three main reasons lead to the variability of ground motions: the wave passage effect resulting from the finite velocity of traveling waves; the incoherence effect that arises from the multiple reflections, refractions, and the super-positioning of the waves induced by these two factors; and the differential site-response effect owing to the filter effects of soil types [16-18]. Many studies have considered the simulation of spatially varying ground motions due to rare recordings of earthquake ground motions at close sites [18-20]. The theoretical seismological approach is a method that considers the whole procedure in which waves travel from the fault rupture to the ground surface. It is comprehensive, but very complex as it requires detailed knowledge of fault sizes, rupture mechanisms, distance from the epicenter, etc. Moreover, these data are usually not fully available [19]. Therefore, a simpler method, the stochastic approach, which assumes that the ground motion is a response of the bedrock that filtered by the soil layers, is adopted widely [21-23]. There are two main simulation methods in the stochastic approach: unconditional and conditional simulation. Unconditional simulation obtains ground motions from a power spectral density function at a given site. Although such simulated motions provide valuable information for the performance evaluation of long bridges, they are, to a certain degree, artificial [24]. Conditional simulation permits the use of one or more predefined ground motions at a reference site, and the simulated motions can possess the physical characteristics of the predefined motions to some extent, such as non-stationarity in amplitude and frequency content [16]. Thus, in this paper, the conditioned simulation method proposed by Konakli [17] is adopted to simulate the spatially varying ground motions.

An appropriate train-track-bridge coupled model is critical for estimating the train running safety, one of the key components of which is the wheel-rail contact model. The 3D rolling wheel-rail contact model is used, which considers the geometries of the wheel and rail profiles, as it is a robust and adequate method for thoroughly analyzing train-track-bridge interaction under normal operating conditions or in extreme situations such as strong lateral winds or earthquakes [25]. A 31-degrees-of-freedom (DOFs) vehicle model established by the multi-body dynamics and a track-bridge model built by using the finite element method (FEM) form the rest part of the traintrack-bridge coupled model. To improve the computational efficiency, the multi-time-step method proposed by the authors in previous studies is also adopted [25-27]. A CRH3 high-speed train passing through a three-tower cable-stayed bridge under earthquake excitation is taken as the numerical example. The responses of the train-trackbridge coupled system are calculated and compared with the case of a uniform earthquake excitation, a traveling earthquake excitation, and the spatially varying earthquake excitation with different soil types.

\section{Conditional simulation of spatially varying ground motions}

As previously mentioned, the variabilities of ground motions at different sites should contain not only the wave passage effect but also the incoherence effect and the siteresponse effect. In this paper, the methodology proposed by Konakli [17] is adopted to simulate the spatially varying ground motions and is introduced briefly hereinafter.

Assume that the number of sites is $n$. In conditional simulation, the realization of the ground motion at one or more sites, called the known sites, is given, and acceleration time histories at other sites, called the target sites, need to be generated. Here, we consider the case when the first site is the known site, and other sites are the target sites.

Let $N$ be the number of discrete observations of the given acceleration time history, which is sampled at equal time intervals $\Delta t$. We denote the corresponding time instants $t_{i}=i \Delta t, i=0,1, \ldots, N-1$. It is well known that such an array of processes can be represented in terms of the finite Fourier series: 


$$
\begin{aligned}
a_{1}\left(t_{i}\right)= & A_{01}+\sum_{p=1}^{\frac{N}{2}-1}\left[A_{p 1} \cos \left(\omega_{p} t_{i}\right)+B_{p 1} \sin \left(\omega_{p} t_{i}\right)\right] \\
& +(-1)^{i} A_{(N / 2) 1},
\end{aligned}
$$

where $a_{1}$ is the given acceleration at the first site; $\omega_{p}=$ $2 \pi p /(N \Delta t)$ is the $p$ th frequency; $A_{01}$ is a constant term; and $\left(A_{p 1}, B_{p 1}\right)$ are vectors of the random Fourier coefficients at the frequency $\omega_{p}$. The auto-power spectral density (autoPSD) function of the given acceleration, $G_{11}(\omega)$, can then be estimated by the periodogram [28]. The relationship between the auto-PSD (power spectral density) at the first site and the $k$ th target site can be expressed as

$G_{k k}(\omega)=G_{11}(\omega) \frac{\left|h_{k}(\omega)\right|^{2}}{\left|h_{1}(\omega)\right|^{2}}$,

where $h_{k}(\omega)$ represents the frequency response function (FRF) of site $k$. The theoretical model of FRF given by Şafak [29] is adopted here:

$h_{k}(\omega)=\frac{\left(1+r_{k}-\operatorname{sgn}(\omega) \frac{\mathrm{i}}{4 Q_{k}}\right) \exp \left[-\mathrm{i} \omega \tau_{k}\left(1-\operatorname{sgn}(\omega) \frac{\mathrm{i}}{2 Q_{k}}\right)\right]}{1+\left(r_{k}-\operatorname{sgn}(\omega) \frac{\mathrm{i}}{4 Q_{k}}\right) \exp \left[-\mathrm{i} \omega \tau_{k}\left(1-\operatorname{sgn}(\omega) \frac{\mathrm{i}}{2 Q_{k}}\right)\right]}$,

where $\tau_{k}$ is the time it takes for waves to travel from the bedrock to the ground surface; $Q_{k}$ is a quality factor with $Q_{k}=\frac{1}{2 \zeta_{k}}$ ( $\zeta_{k}$ represents the damping ratio at the $k$ th location); $r_{k}$ is the reflection coefficient of vertically propagating waves; $\mathrm{i}$ is the unit imaginary number and $\operatorname{sgn}(\cdot)$ is the signum function. The cross-PSD between sites $k$ and $l$ is given by

$G_{k l}(\omega)=\gamma_{k l}(\omega)\left[G_{k k}(\omega) G_{l l}(\omega)\right]^{1 / 2}$,

where $\gamma_{k l}(\omega)$ represents the coherency function. Der Kiureghian [18] developed a coherency model for earthquake ground motions that accounts for spatial variability due to the incoherence, wave passage, and site-response effects, and the model can be expressed as

$$
\begin{aligned}
\gamma_{k l}(\omega)= & \exp \left[-\left(\frac{\alpha d_{k l} \omega}{v_{\mathrm{s}}}\right)^{2}\right] \\
& \cdot \exp \left[\mathrm{i} \tan ^{-1} \frac{\operatorname{Im}\left[h_{k}(\omega) h_{l}(-\omega)\right]}{\operatorname{Re}\left[h_{k}(\omega) h_{l}(-\omega)\right]}\right] .
\end{aligned}
$$

The two terms in Eq. (5) describe the incoherence effect and site-response effects, respectively. It should be noted that the wave passage effect is treated as a deterministic time shift after the simulation. In Eq. (5), $v_{\mathrm{s}}$ is the shearwave velocity of the soil medium; $d_{k l}$ is the distance between the sites $k$ and $l ; \alpha$ is an incoherence coefficient.

Let the set of zero-mean Fourier coefficients at the frequency $\omega_{p}$ for all $n$ sites be expressed as $\boldsymbol{X}_{p}=$
$\left[A_{p 1} B_{p 1} \ldots A_{p n} B_{p n}\right]$ and the $2 n \times 2 n$ covariance matrix of these coefficients $\boldsymbol{\Sigma}_{p p}$. By separating $\boldsymbol{X}_{p}$ into the Fourier coefficient of the known site $\boldsymbol{X}_{p 1}=\left[A_{p 1} B_{p 1}\right]$ and that of the target sites $\boldsymbol{X}_{p 2}=\left[A_{p 2} B_{p 2} \ldots A_{p n} B_{p n}\right]$, the covariance matrix $\boldsymbol{\Sigma}_{p p}$ can be expressed as

$\boldsymbol{\Sigma}_{p p}=\left[\begin{array}{ll}\boldsymbol{\Sigma}_{p p, 11} & \boldsymbol{\Sigma}_{p p, 12} \\ \boldsymbol{\Sigma}_{p p, 21} & \boldsymbol{\Sigma}_{p p, 22}\end{array}\right]_{2 n \times 2 n}$.

It is well known that the conditional distribution of $\boldsymbol{X}_{p 2}$ is jointly normal [17] with a mean

$\boldsymbol{M}_{p, 2 \mid 1}=\boldsymbol{\Sigma}_{p p, 21}\left(\boldsymbol{\Sigma}_{p p, 11}\right)^{-1} \boldsymbol{x}_{p 1}$,

and covariance matrix

$\boldsymbol{\Sigma}_{p, 22 \mid 11}=\boldsymbol{\Sigma}_{p p, 22}-\boldsymbol{\Sigma}_{p p, 21}\left(\boldsymbol{\Sigma}_{p p, 11}\right)^{-1} \boldsymbol{\Sigma}_{p p, 12}$.

At each frequency, $\omega_{p}=2 \pi p /(N \Delta t), p=1,2, \ldots, N / 2$, a sample set of Fourier coefficients for the target sites is obtained as

$\boldsymbol{x}_{p 2}=\boldsymbol{M}_{p, 2 \mid 1}+\boldsymbol{L}_{p}^{\mathrm{T}} z_{p}$,

where $\boldsymbol{L}_{p}$ is an upper triangular matrix that $\boldsymbol{L}_{p}^{\mathrm{T}} \boldsymbol{L}_{p}=\boldsymbol{\Sigma}_{p, 22 \mid 11}$, and $z_{p}$ is a vector of $2(n-1)$ uncorrelated standard normal variables. Then, $\boldsymbol{x}_{p 2}$ is applied to Eq. (1) to generate the realizations of acceleration time histories at the target sites. Finally, a deterministic time shift of the simulated time histories is made in accordance with the formula $d_{k l}^{\mathrm{L}} / v_{\text {app }}$ to account for the wave passage effect. $d_{k l}^{\mathrm{L}}$ is the projection of the interstation distance along the direction of wave propagation on the ground surface, and $v_{\text {app }}$ is the apparent surface wave velocity.

\section{Train-track-bridge model and multi-time-step method}

\subsection{Train-track-bridge model under earthquake excitation}

The train-track-bridge model is same as that adopted in the authors' previous study [27]. To apply the multi-time-step (MTS) method, the train-track-bridge coupled system is separated into the train subsystem, the track subsystem, and the bridge subsystem [27], as shown in Fig. 1. The train subsystem and the track subsystem are coupled by the 3D wheel-rail rolling contact model [30]. The track subsystem and the bridge subsystem are coupled by the interaction forces between them. The train subsystem and the track subsystem adopt a fine time step to obtain the high-frequency vibration between wheel and rail, while the bridge subsystem adopts a coarse time step to reduce the computational efforts. 

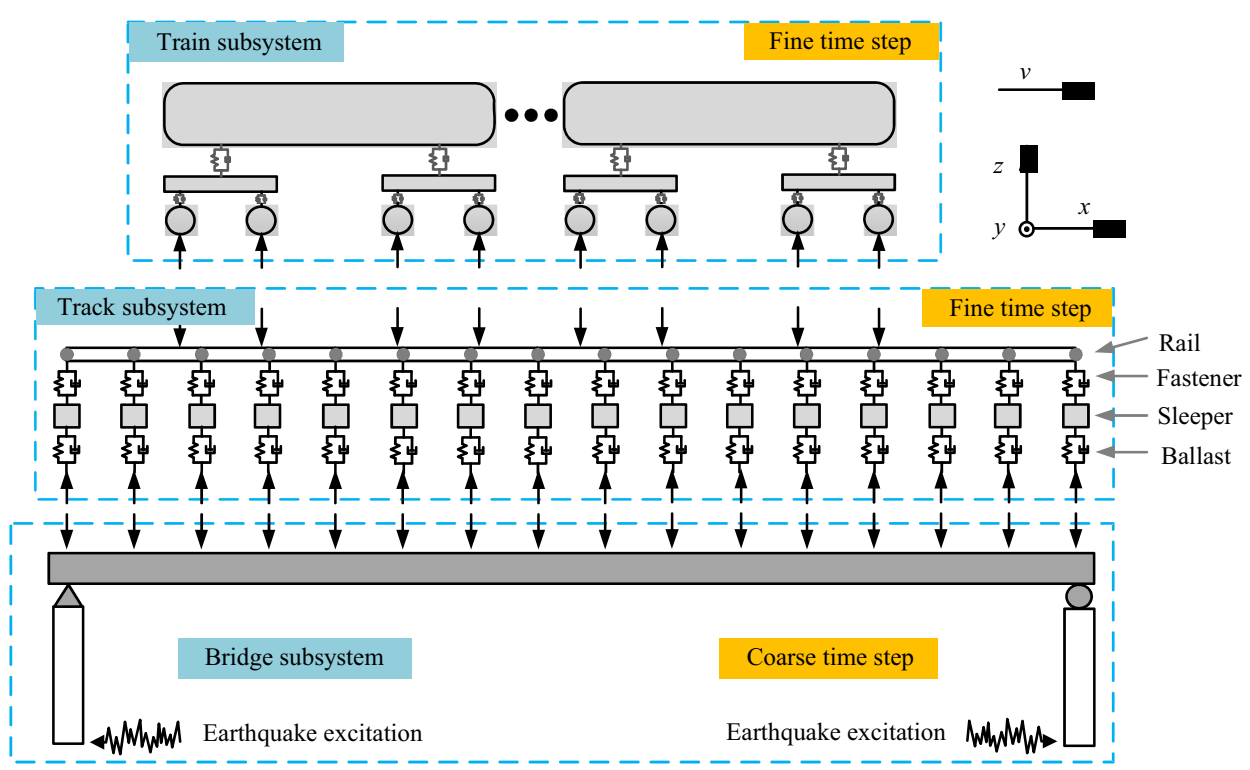

Fig. 1 The train-track-bridge coupled system under earthquake excitation

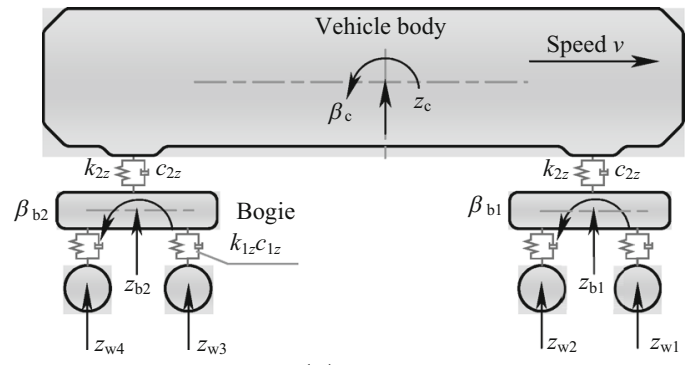

(a) Side view

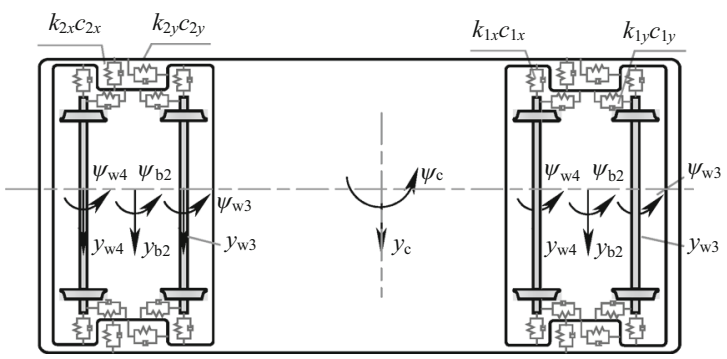

(c) Top view

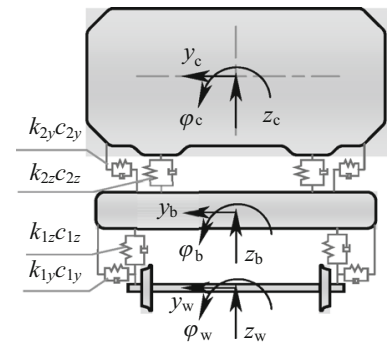

(b) Front view

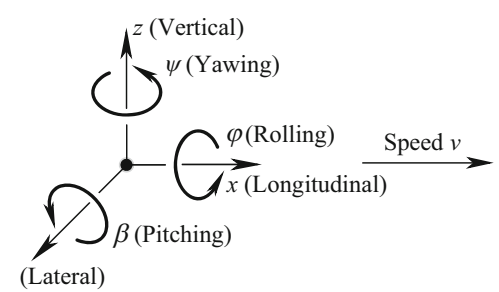

(d) Sign convention for vehicle

Fig. 2 Vehicle model with corresponding DOFs

The train consists of a set of vehicles whose models are established using multi-body dynamics. Each vehicle has four wheelsets, two bogies, and one car body. These components are treated as rigid bodies by neglecting their elastic deformation. Each car body and bogie has five DOFs, which are the lateral, rolling, yawing, vertical, and pitching directions. Each wheelset has four DOFs by removing the pitching direction. Thus, each vehicle has 31
DOFs. Spring-damping elements are used to model the primary suspension between the wheelsets and the bogies, and the secondary suspensions between the bogies and the car body.

Figure 2 shows the modeling, dimensions, and parameters of a train car. The longitudinal, lateral, vertical, rolling, pitching, and yawing directions are denoted by $x, y$, $z, \varphi, \beta$, and $\psi$, respectively, and $k$ and $c$ represent stiffness 


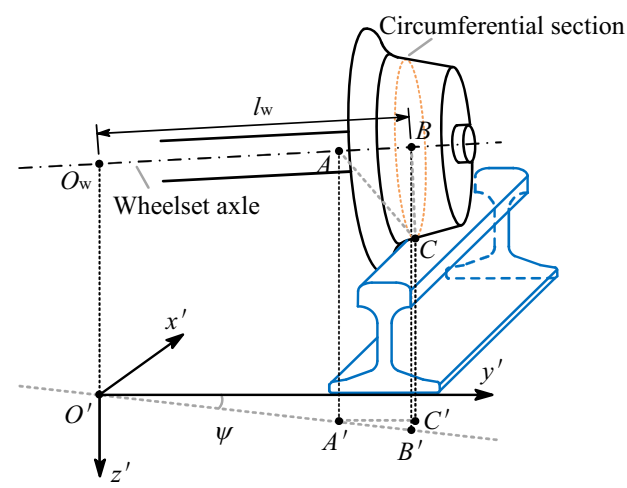

(a) Wheel- rail contact geometry relationship

Fig. 3 Geometric relationship of wheel-rail contact

and damping coefficients, respectively. The car body, bogie, and wheelset are denoted by the subscripts c, b, and $\mathrm{w}$, respectively.

The vibration equations of the train can be written as

$\boldsymbol{M}_{\mathrm{v}} \ddot{\boldsymbol{X}}_{\mathrm{v}}+\boldsymbol{C}_{\mathrm{v}} \dot{\boldsymbol{X}}_{\mathrm{v}}+\boldsymbol{K}_{\mathrm{v}} \boldsymbol{X}_{\mathrm{v}}=\boldsymbol{F}_{\mathrm{vg}}-\boldsymbol{F}_{\mathrm{wr}}$

where $\boldsymbol{M}_{\mathrm{v}}, \boldsymbol{C}_{\mathrm{v}}$, and $\boldsymbol{K}_{\mathrm{v}}$ represent the mass, damping, stiffness matrices of the train, respectively; $\boldsymbol{X}_{\mathrm{v}}$ is the displacement vector; $\boldsymbol{F}_{\mathrm{vg}}$ and $\boldsymbol{F}_{\mathrm{wr}}$ are the self-weight of the train and the wheel-rail interaction force, respectively.

The track structure serves as an intermediate structural part to transfer the trainload to the bridge and, at the same time, filters the high-frequency vibrations induced by the wheel-rail contact [27]. Therefore, the track structure should be considered when evaluating the running safety and riding comfort of a train traversing a bridge [31].

The ballast track structure is composed mainly of the rails, the fasteners, the sleepers, and the ballast, as shown in Fig. 1. The rails and sleepers are modeled using beam elements, and the fasteners and ballast are modeled using spring-damping elements in four directions. The mass of the ballast is added to the mass of the bridge.

The vibration equations of the track structure can be written as

$$
\begin{aligned}
& {\left[\begin{array}{cc}
\boldsymbol{M}_{\mathrm{rr}} & 0 \\
0 & \boldsymbol{M}_{\mathrm{ss}}
\end{array}\right]\left[\begin{array}{c}
\ddot{\boldsymbol{X}}_{\mathrm{r}} \\
\ddot{\boldsymbol{X}}_{\mathrm{s}}
\end{array}\right]+\left[\begin{array}{ll}
\boldsymbol{C}_{\mathrm{rr}} & \boldsymbol{C}_{\mathrm{rs}} \\
\boldsymbol{C}_{\mathrm{sr}} & \boldsymbol{C}_{\mathrm{ss}}
\end{array}\right]\left[\begin{array}{c}
\dot{\boldsymbol{X}}_{\mathrm{r}} \\
\dot{\boldsymbol{X}}_{\mathrm{s}}
\end{array}\right]} \\
& +\left[\begin{array}{ll}
\boldsymbol{K}_{\mathrm{rr}} & \boldsymbol{K}_{\mathrm{rs}} \\
\boldsymbol{K}_{\mathrm{sr}} & \boldsymbol{K}_{\mathrm{ss}}
\end{array}\right]\left[\begin{array}{l}
\boldsymbol{X}_{\mathrm{r}} \\
\boldsymbol{X}_{\mathrm{s}}
\end{array}\right] \\
& =\left[\begin{array}{l}
\boldsymbol{F}_{\mathrm{wr}} \\
\boldsymbol{F}_{\Gamma \mathrm{s}}
\end{array}\right]
\end{aligned}
$$

where the subscripts ' $r$ ' and ' $s$ ' denote the rail and sleeper, respectively; $\boldsymbol{M}_{\mathrm{rr}}, \boldsymbol{C}_{\mathrm{rr}}$, and $\boldsymbol{K}_{\mathrm{rr}}$ represent the mass, damping, and stiffness of the rail, respectively; $\boldsymbol{X}_{\mathrm{r}}$ is the displacement vector of the rail. In this study, the only external forces of the rail are the wheel-rail contact forces, $\boldsymbol{F}_{\mathrm{wr}}$, and the only external forces of the sleeper are the supporting forces given by the bridge, $\boldsymbol{F}_{\Gamma \mathrm{s}}$.

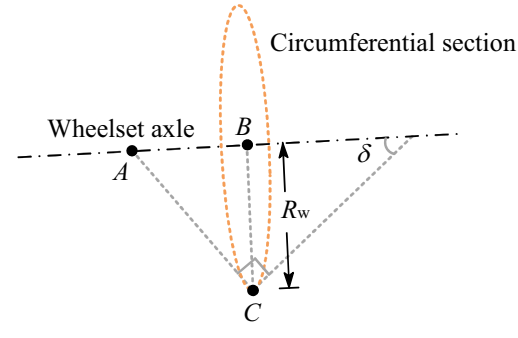

(b) Enlarged part of contact zone

The bridge structures are modeled with the FE method. For different bridge structure types, beam elements, pole elements, shell elements, and other types of element are used for modeling individual components. The vibration equations of the bridge under earthquake can be written as

$\boldsymbol{M}_{\mathrm{b}} \ddot{\boldsymbol{X}}_{\mathrm{b}}+\boldsymbol{C}_{\mathrm{b}} \dot{\boldsymbol{X}}_{\mathrm{b}}+\boldsymbol{K}_{\mathrm{b}} \boldsymbol{X}_{\mathrm{b}}=\boldsymbol{F}_{\mathrm{bt}}+\boldsymbol{F}_{\mathrm{EA}}$,

where $\boldsymbol{M}_{\mathrm{b}}, \boldsymbol{C}_{\mathrm{b}}$, and $\boldsymbol{K}_{\mathrm{b}}$ are the mass, damping, and stiffness matrix of the bridge, respectively; $\boldsymbol{X}_{\mathrm{b}}$ is the displacement vector of the bridge. Two kinds of forces act on the bridge: $\boldsymbol{F}_{\text {bt }}$, the forces exerted by the track structure, and $\boldsymbol{F}_{\mathrm{EA}}$, the forces simulating earthquake excitation, which is obtained through the big mass method [12].

The 3D wheel-rail rolling contact model proposed by Chen and Zhai $[1,3,30]$ is adopted in this paper. Figure 3 shows a general wheel-rail contact condition, where point $B$ is the center of a circumferential section of the wheel and $C$ is a wheel-rail contact point. The coordinates of the contact point can be determined by trace curve scanning, and then, the compressive deformation between the wheel and rail in the normal direction can be obtained. The normal and creep forces between wheel and rail are obtained using the nonlinear elastic Hertzian contact theory and the Kalker creep theory.

Detailed introduction of the train-track-bridge coupled model, including the wheel-rail interaction model and the expression of the forces between the subsystems, can be found in Ref. [27].

\subsection{Multi-time-step method}

The MTS method proposed in the authors' previous study [27] is adopted in this paper to reduce computational efforts. As explained, the train-track-bridge coupled system is separated into the train subsystem, the track subsystem, and the bridge subsystem. The responses of each subsystem are calculated by applying a step-by-step integration method, such as the Newmark- $\beta$ method. A fine 


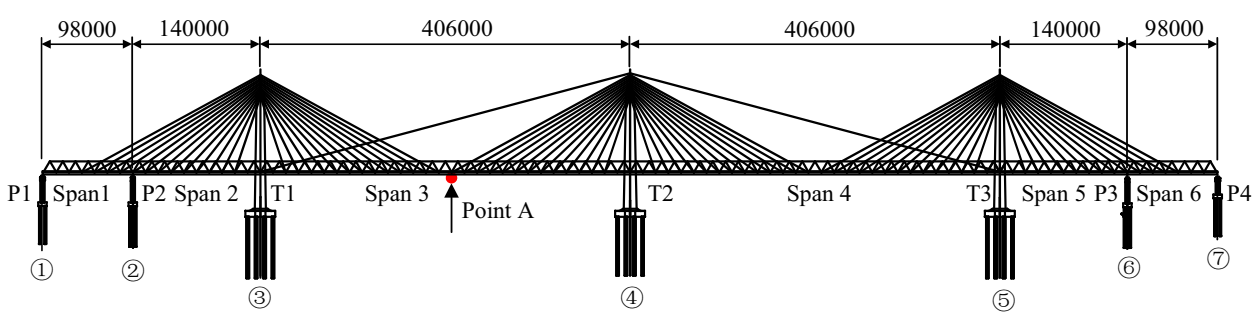

Fig. 4 Overall arrangement of the bridge (in $\mathrm{mm}$ )

time step is adopted to solve the vibration equations of the train subsystem and the track subsystem to obtain the highfrequency vibration between wheel and rail, whereas a coarse time step is adopted for the bridge subsystem to reduce the computational effort. A brief introduction to the calculation procedure is presented next.

Let $\Delta t$ represent the fine time step, $\Delta T$ represent the coarse time step, and $\Delta T=m \Delta t$. At each coarse time step, the responses of the bridge subsystem at the current coarse time step, i.e., $\boldsymbol{X}_{\mathrm{b}}^{m}, \dot{\boldsymbol{X}}_{\mathrm{b}}^{m}$, and $\ddot{\boldsymbol{X}}_{\mathrm{b}}^{m}$, are obtained firstly by applying the forces given by the track structure at the previous coarse time step, $\boldsymbol{F}_{\mathrm{bt}}^{0}$, and the forces of the earthquake excitation at the current coarse time step, on the bridge. This step is the critical step of the MTS method. It is assumed that the forces of the bridge imposed by the track structure remain unchanged when the calculation moves to the next coarse time step. That sounds unreasonable, but the accuracy of the results is satisfying when the assumption is adopted [27]. The responses of the bridge at the $j$ th $(j=1,2, \ldots, m)$ fine time step can then be obtained by linearly interpolating the bridge responses between the current coarse time step and the previous coarse time step:

$\dot{\boldsymbol{X}}_{\mathrm{b}}^{j}=\left(1-\frac{j}{m}\right) \dot{\boldsymbol{X}}_{\mathrm{b}}^{0}+\left(\frac{j}{m}\right) \dot{\boldsymbol{X}}_{\mathrm{b}}^{m}$,

$\boldsymbol{X}_{\mathrm{b}}^{j}=\left(1-\frac{j}{m}\right) \boldsymbol{X}_{\mathrm{b}}^{0}+\left(\frac{j}{m}\right) \boldsymbol{X}_{\mathrm{b}}^{m}$

Then, the responses of the train and track subsystems at the $j$ th fine time step can be obtained by calculating the forces vector $\boldsymbol{F}_{\Gamma \mathrm{s}}^{j}$ using the bridge responses at the $j$ th fine time step. It should be noted that the wheel-rail interaction forces at the $j$ th fine time step, $\boldsymbol{F}_{\mathrm{wr}}^{j}$, are calculated using the responses of the train and track at the $(j-1)$ th fine time step. This method is appropriate when a sufficiently small time step is adopted [32].

At this point, the solution from $t_{0}$ to $t_{m}$ is complete, and the process is repeated for the subsequent cycle with a $\Delta T$ time step. A detailed introduction to the calculation procedure of the MTS method was provided in Ref. [27].

\section{Case study}

\subsection{A three-tower cable-stayed railway bridge}

A three-tower cable-stayed railway bridge is considered herein for the numerical example. The bridge has an overall length of $1288 \mathrm{~m}$ with two 406-m main spans and two side spans of $98 \mathrm{~m}$ and $140 \mathrm{~m}$ in length, as shown in Fig. 4. The three towers with $157 \mathrm{~m}$ in height are inverted Y-shapes (Fig. 5a), where the stiffening beam is stayed with 158 cables. The ballast track structure is laid on the bridge deck, which is stiffened by U-shape and T-shape stiffeners and the main girder on each side, as shown in Fig. 5b. The 3D finite element model of the cable-stayed bridge is presented in Fig. 6. The rails, sleepers, piers, and towers are modeled using beam elements based on the actual cross-sectional properties. Distributed uniaxial spring-dashpot units are used to simulate the elasticity behavior of the ballast and fasteners. Based on the equivalent orthotropic material modeling method presented by Cai [33], the equivalent shell element is used to model the bridge deck with U-shaped and T-shaped stiffeners. Each cable is modeled by a single straight truss element, and the equivalent modulus $E_{\mathrm{eq}}$ is as given by Ernst [34]. Information as to the vibration mode of the bridge is shown in Fig. 7 and Table 1.

\subsection{Result comparison and discussion}

A CRH3 high-speed train traversing the bridge under earthquake excitation is taken as a numerical example to investigate the influence of spatially varying ground motion. The train consists of eight vehicles, MTMTTMTM, where $\mathrm{M}$ stands for the motored tractor and $\mathrm{T}$ the trailer. The parameters of the train can be found in Ref. [35]. The track irregularities are sampled from the German low-disturbance spectrum [36].

As shown in Fig. 4, the whole bridge has seven supports, which are four piers and three towers. Here, we consider the first support as the known site and the other supports as the target sites. Three different soil types: firm, medium, and soft, are considered for different supports. 


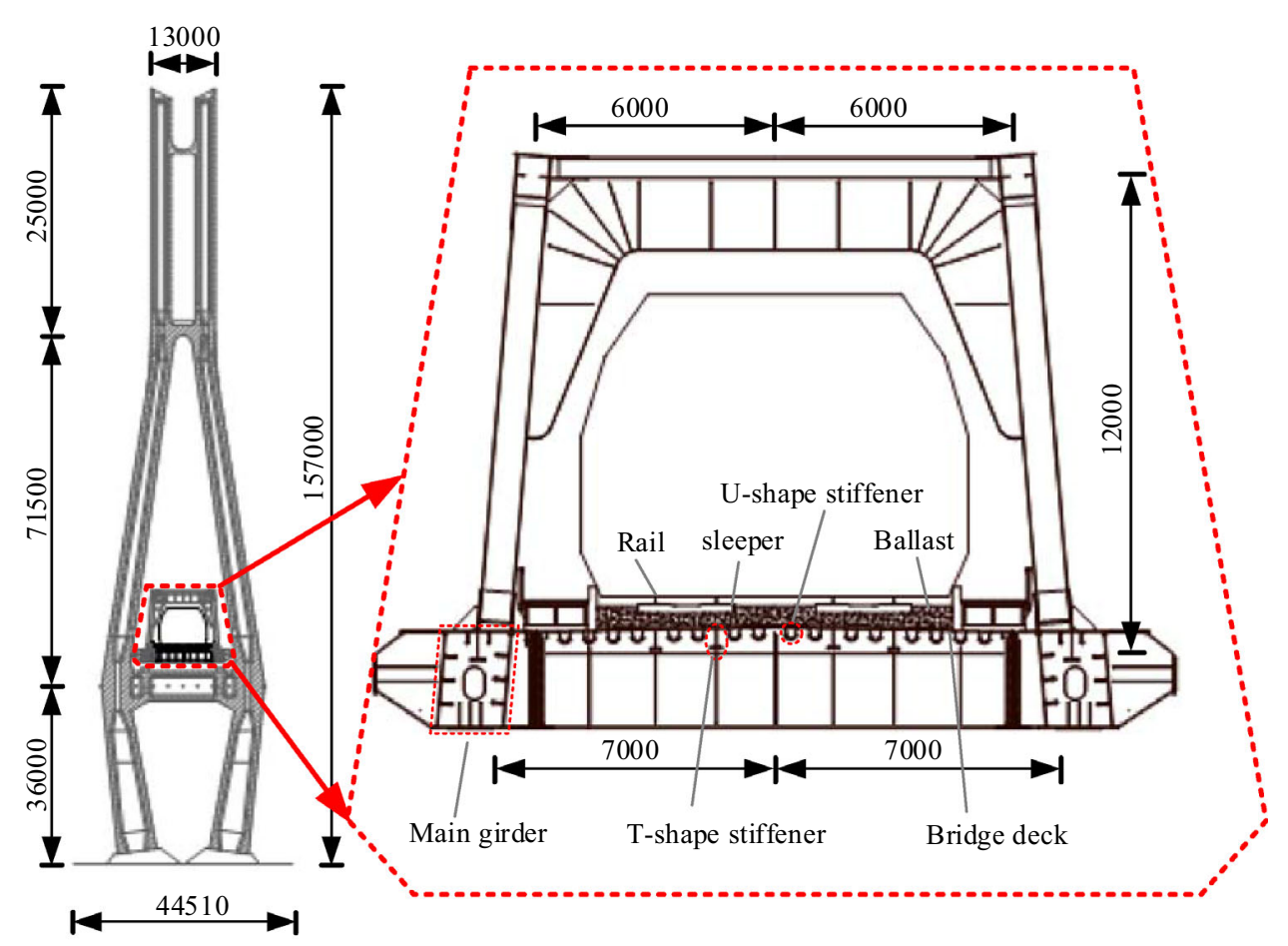

(a)

(b)

Fig. 5 Components of the cable-stayed bridge: a dimensions of the tower; $\mathbf{b}$ cross section of the stiffening beam (in $\mathrm{mm}$ )

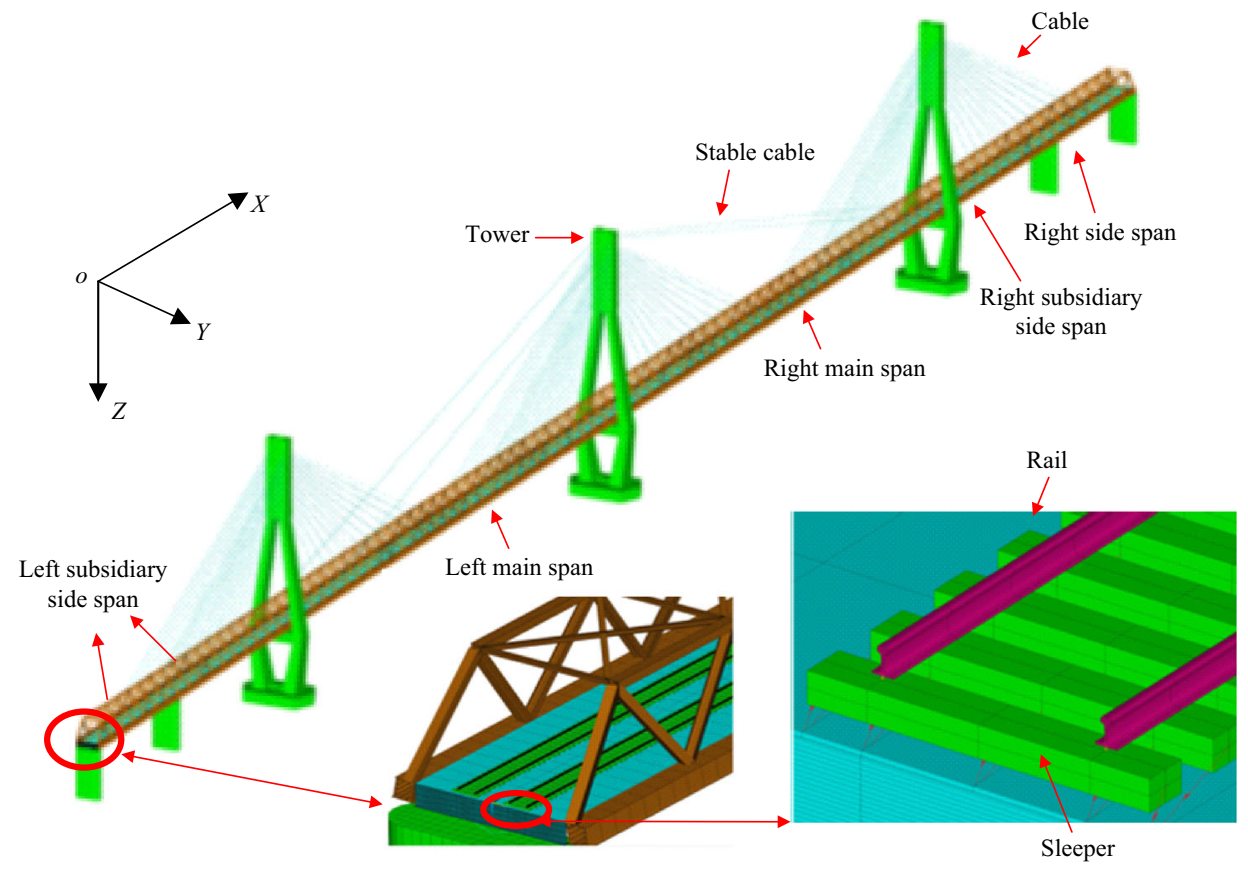

Fig. 6 Three-dimensional finite element model of the bridge

The parameters for the different soil types are given in Table $2[16,37]$, in which $\zeta_{k}, \mathrm{v}_{\mathrm{s}}, \tau_{k}$, and $r_{k}$ represent the damping ratio, shear-wave velocity of soil, the time it takes for waves to travel from the bedrock to the ground surface, and the reflection coefficient of vertically propagating waves, respectively. 


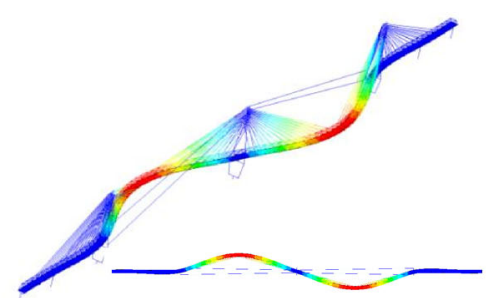

(a) First vibration mode

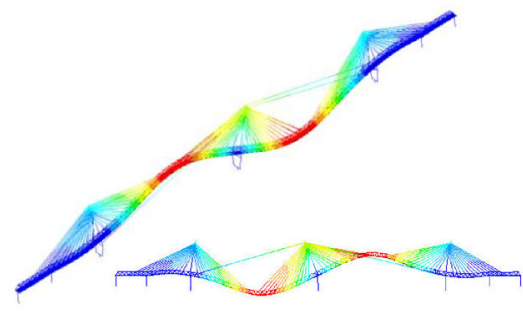

(c) Third vibration mode

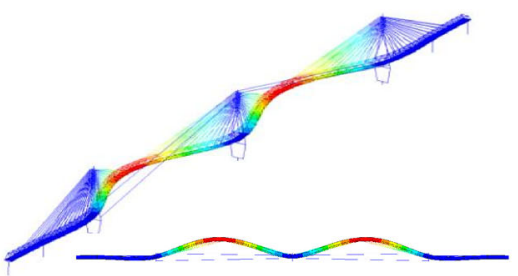

(b) Second vibration mode

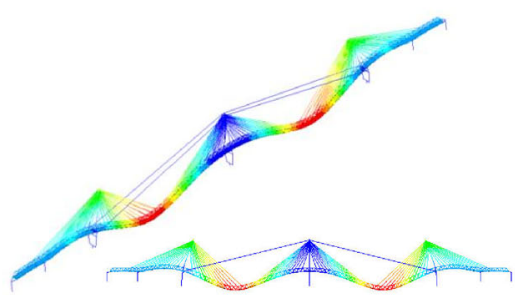

(d) Fourth vibration mode

Fig. 7 First four vibration modes of the bridge

Table 1 Information about the bridge vibration mode

\begin{tabular}{lll}
\hline Mode no. & Frequency $(\mathrm{Hz})$ & Mode shape \\
\hline 1 & 0.270 & Asymmetrical lateral bending \\
2 & 0.317 & Symmetrical lateral bending \\
3 & 0.439 & Asymmetrical vertical bending + tower longitudinal bending \\
4 & 0.594 & Symmetrical vertical bending + tower longitudinal bending \\
\hline
\end{tabular}

Table 2 Parameters of different sites

\begin{tabular}{lllll}
\hline Soil type & $\zeta_{k}$ & $\mathrm{v}_{\mathrm{s}}(\mathrm{m} / \mathrm{s})$ & $\tau_{k}(\mathrm{~s})$ & $r_{k}$ \\
\hline Firm & 0.6 & 400 & 0.2 & 0.42 \\
Medium & 0.4 & 300 & 0.3 & 0.69 \\
Soft & 0.2 & 200 & 0.6 & 0.78
\end{tabular}

The soil beneath the four piers, i.e., P1, P2, P3, and P4 (Fig. 4), is assumed to be firm, whereas the soil below the three towers, i.e., T1, T2, and T3 (Fig. 4), varies. Assuming that the soil is softer when the location is closer to the river center, three combinations of local soil conditions are considered in this study: FFMMMFF, FFMSMFF, and FFSSSFF. Here, F, M, and S represent firm, medium, and soft soil types, respectively. Therefore, 12 cases are presented in order to investigate the influence of the spatially varying ground motion on the train running safety, as illustrated in Table 3. Cases 1-6 are below the design speed of the bridge, i.e., $160 \mathrm{~km} / \mathrm{h}$. The first three cases represent traditional earthquake analysis cases, in which no earthquake, a uniform earthquake, and an earthquake with wave passage effect, respectively, are considered, while cases 4-6 consider spatially varying ground motion with
Table 3 Information about cases

\begin{tabular}{llll}
\hline Cases & $\begin{array}{l}\text { Train speed } \\
(\mathrm{km} / \mathrm{h})\end{array}$ & Earthquake & Soil condition \\
\hline 1 & 160 & No earthquake & - \\
2 & 160 & Uniform earthquake & - \\
3 & 160 & Considering wave passage & - \\
4 & 160 & Spatial varying & FFMMMFF \\
5 & 160 & Spatial varying & FFMSMFF \\
6 & 160 & Spatial varying & FFSSSFF \\
7 & 250 & No earthquake & - \\
8 & 250 & Uniform earthquake & - \\
9 & 250 & Considering wave passage & - \\
10 & 250 & Spatial varying & FFMMMFF \\
11 & 250 & Spatial varying & FFMSMFF \\
12 & 250 & Spatial varying & FFSSSFF \\
\hline
\end{tabular}

different local soil conditions; cases 7-12 are the same as cases $1-6$, except that the train speed is the general operation speed, i.e., $250 \mathrm{~km} / \mathrm{h}$. 


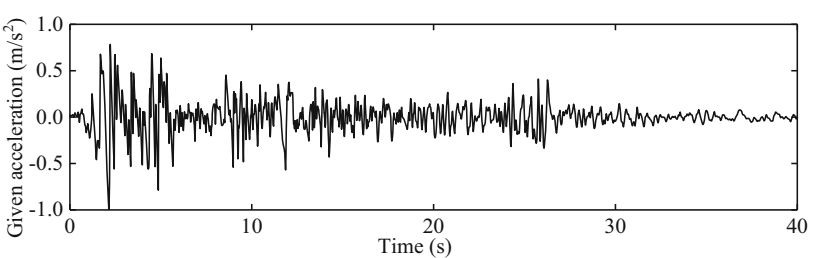

Fig. 8 Time history of the given acceleration

The El-Centro wave, selected from the Pacific Earthquake Engineering Research (PEER) Ground Motion Database, is adopted here as the given acceleration of the first support, as shown in Fig. 8. The peak ground acceleration scale of the earthquake wave is adjusted to $0.1 \mathrm{~g}$, following the earthquake design level of the bridge.

The process introduced in Sect. 2 requires that the time series involved need to be stationary, but the given acceleration is not. Therefore, the acceleration wave needs to be separated into several nearly stationary segments. The characteristics of interest are the variance, predominant frequency, and bandwidth of the given acceleration. According to the work of Rezaeian and Der Kiureghian [38], the instantaneous values of these characteristics are, respectively, represented by the slopes of the integral of squared acceleration in time, the cumulative count of zerolevel up-crossings, and the cumulative count of negative

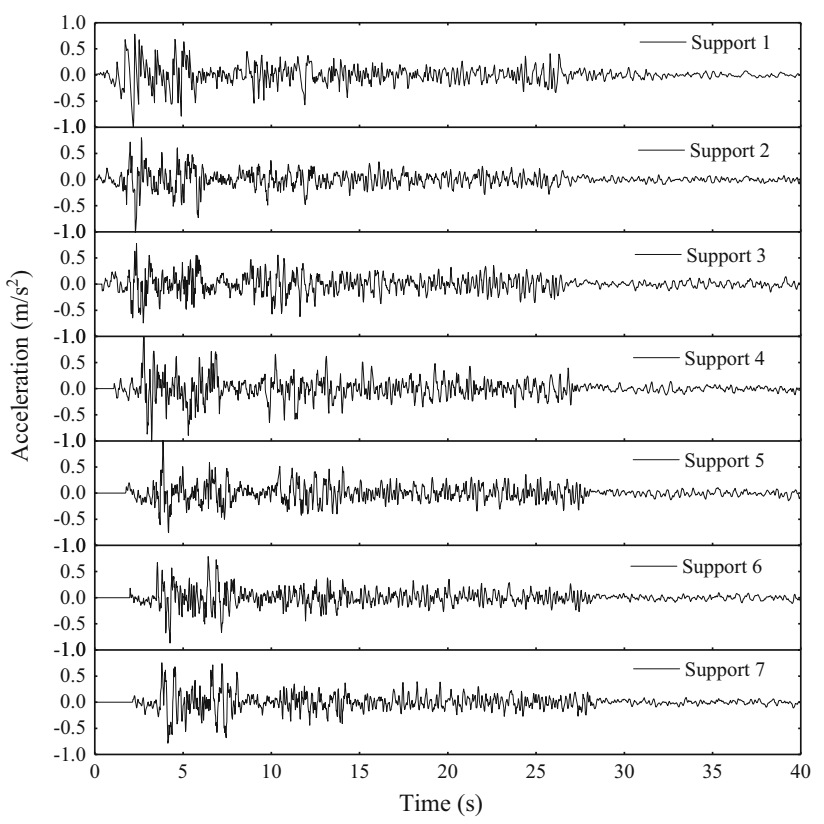

Fig. 10 The given and simulated ground motions of case 5

maxima or positive minima. Figure 9 shows the evolving integral measures of the variance, predominant frequency, and bandwidth, respectively, denoted as $Q_{1}, Q_{2}$, and $Q_{3}$. The vertical dashed lines demarcate the segments where the slopes of all three curves are more or less constant and,

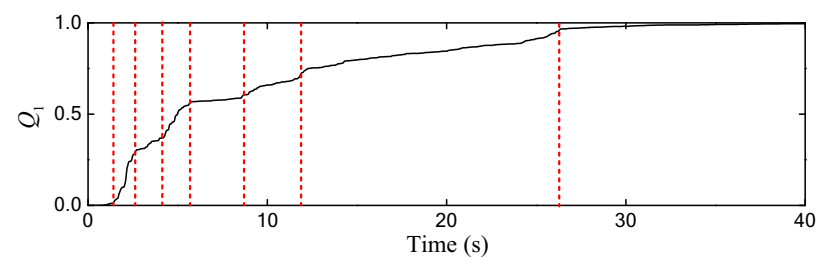

(a) Integral of the squared acceleration in time

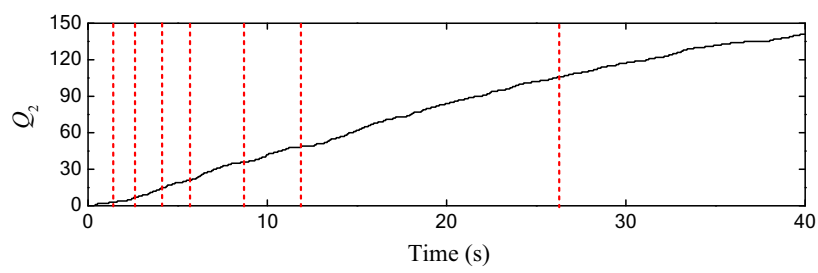

(b) Cumulative count of zero-level up-crossings

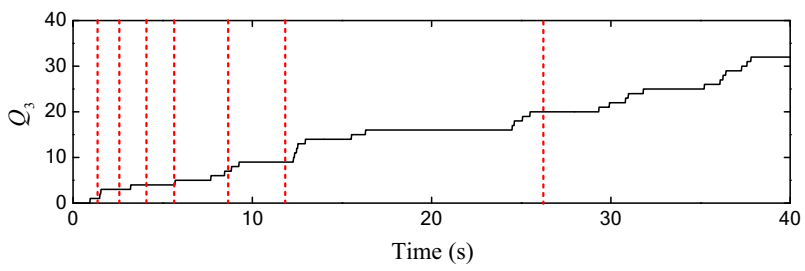

(c) Cumulative count of negative maxima

Fig. 9 Representation of the variance, predominant frequency, and bandwidth of the given acceleration 
hence, the process can be considered nearly stationary. By performing the process introduced in Sect. 2 for each segment, the corresponding segments of the target sites can be obtained and then assembled to the complete acceleration time histories using cosine weighting functions. Then, a deterministic time shift of the simulated time histories is made to account for the wave passage effect. Here, the apparent wave velocity is $600 \mathrm{~m} / \mathrm{s}$, and the direction is the longitudinal direction of the bridge. Figures 10 and 11 show the ground motions and their PSD of case 5; it should be mentioned that the PSD of the ground motions is smoothed by the Tukey window [28].

The lateral acceleration of the first car body, the lateral acceleration of the bridge at point $\mathrm{A}$ (Fig. 4), and the lateral wheel-rail contact force of the first left wheel are

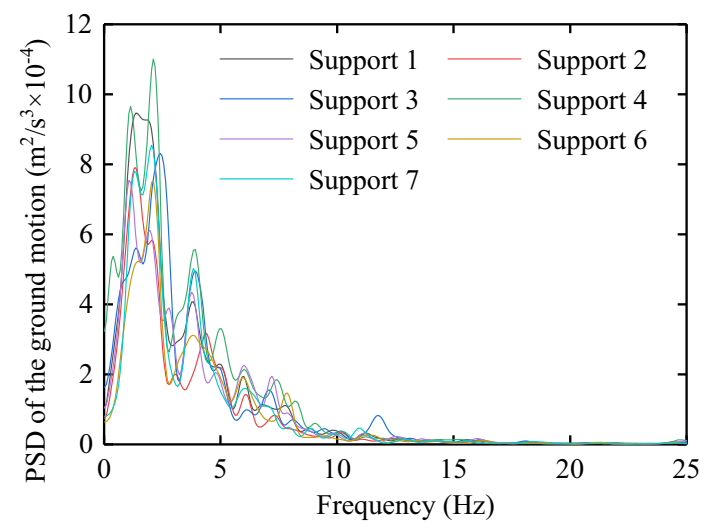

Fig. 11 PSD of the ground motions of case 5 shown in Figs. 12, 13, and 14. The maxima of the running safety indices of all cases are listed in Table 4. Comparisons of the results of no earthquake excitations (cases 1 and 7) and the other cases show that earthquake excitations significantly increase the dynamic responses of the traintrack-bridge coupled system, such as the lateral car-body acceleration and the lateral bridge acceleration, which are insignificantly affected by the track irregularity but significantly affected by the earthquake excitation. Running safety is also affected by the earthquake excitation, as shown in Table 4, where all the indices of running safety increase considerably. At the design speed of $160 \mathrm{~km} / \mathrm{h}$, the running safety still satisfies the code requirement in China [14], which can be expressed as

derailment factor: $Q / P \leq 0.8$,

wheel unloading rate: $\Delta P / \bar{P} \leq 0.6$,

wheel/rail lateral force: $Q \leq 0.85\left(10+P_{\text {st }} / 3\right)$,

where $Q$ and $P$ represent the lateral and vertical wheel-rail contact force, respectively; $\Delta P$ and $\bar{P}$ represent the offload vertical wheel-rail contact force and the average static wheel load, respectively; and $P_{\text {st }}$ denotes the static wheelset load in $\mathrm{kN}$. The allowable lateral wheel-rail force for the CRH3 locomotives is $56.67 \mathrm{kN}$, corresponding to the static load of $140 \mathrm{kN}$. But for the general operation speed of $250 \mathrm{~km} / \mathrm{h}$, the wheel unloading rates in cases $8-12$ and the derailment factor in case 12 exceed the code limit; and all the indices in cases 7-12 are greater than those in cases 1-6. Apparently, the increase in train speed

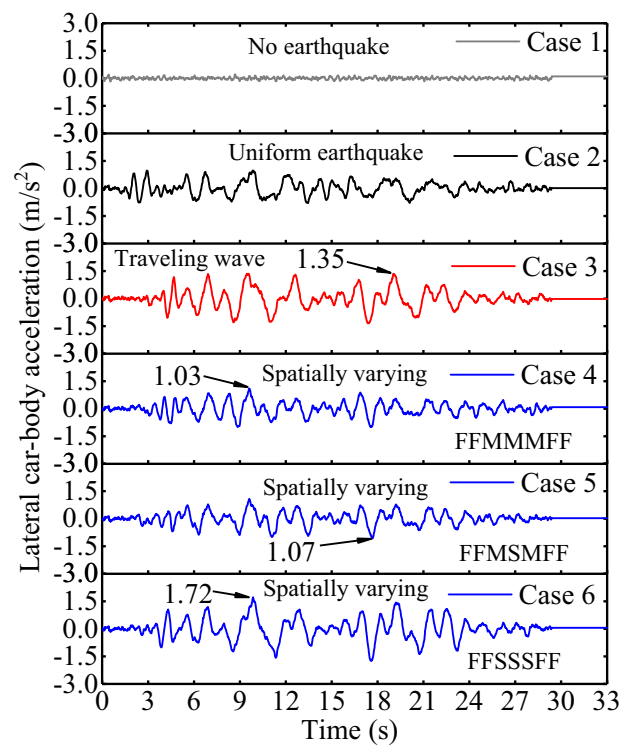

(a)

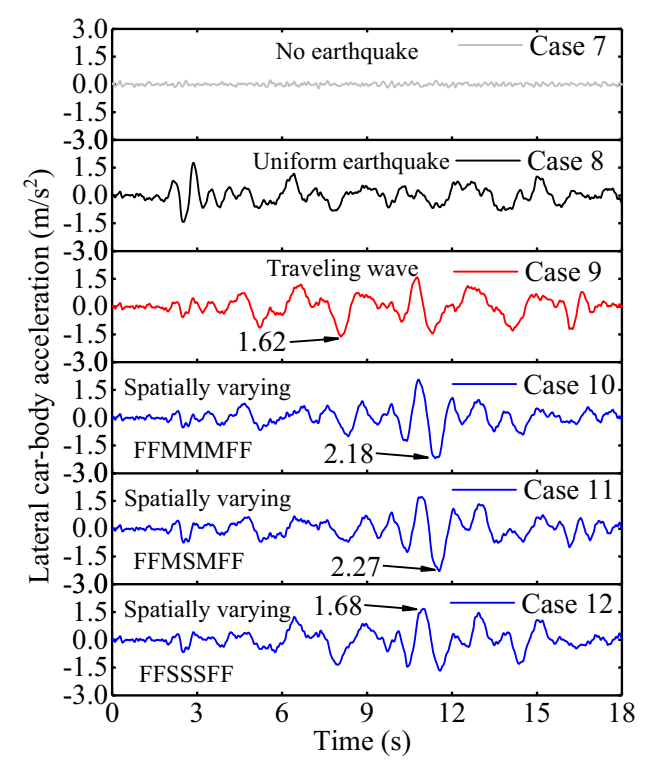

(b)

Fig. 12 Time history of the lateral acceleration of the first car body: a cases 1-6; b cases 7-12 


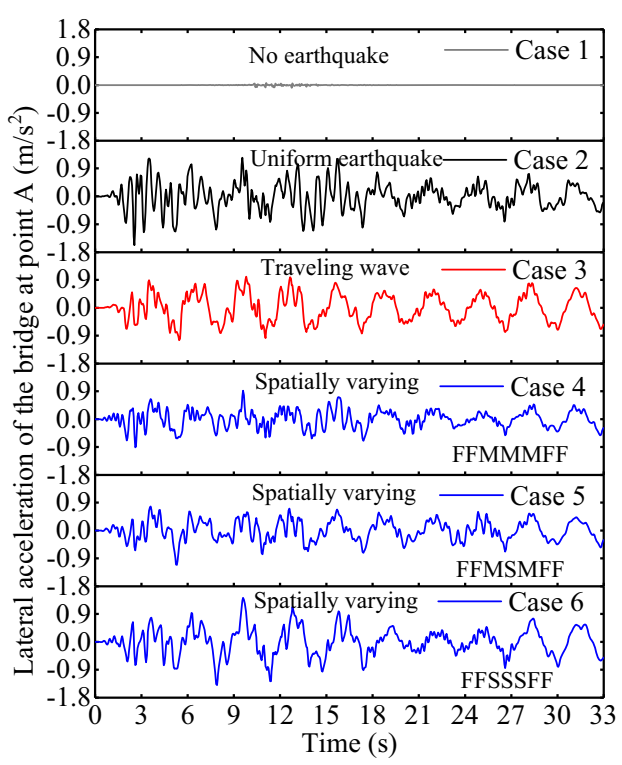

(a)

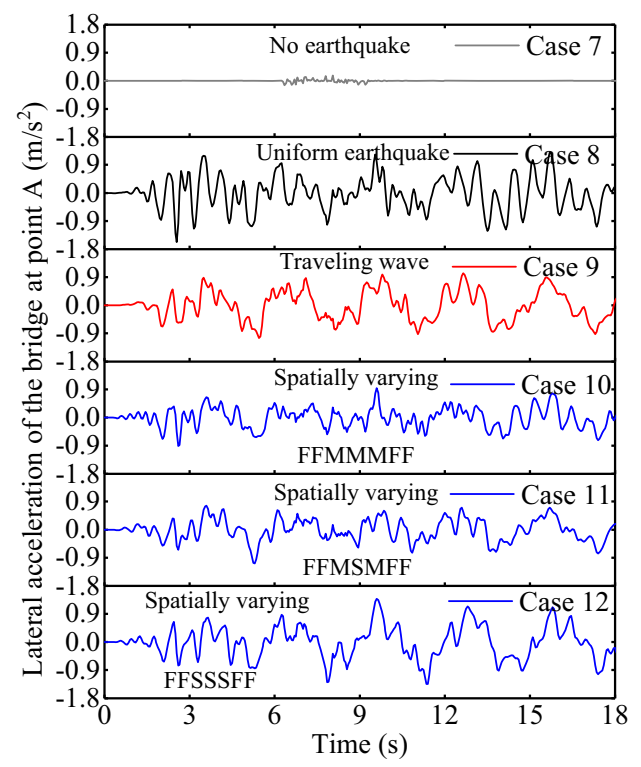

(b)

Fig. 13 Time histories of the lateral acceleration of the bridge at point A: a cases 1-6; b cases 7-12

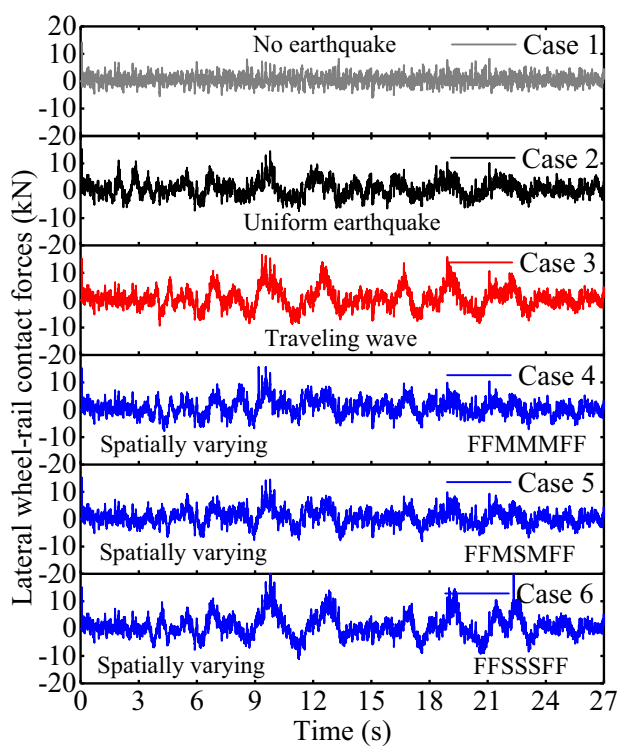

(a)

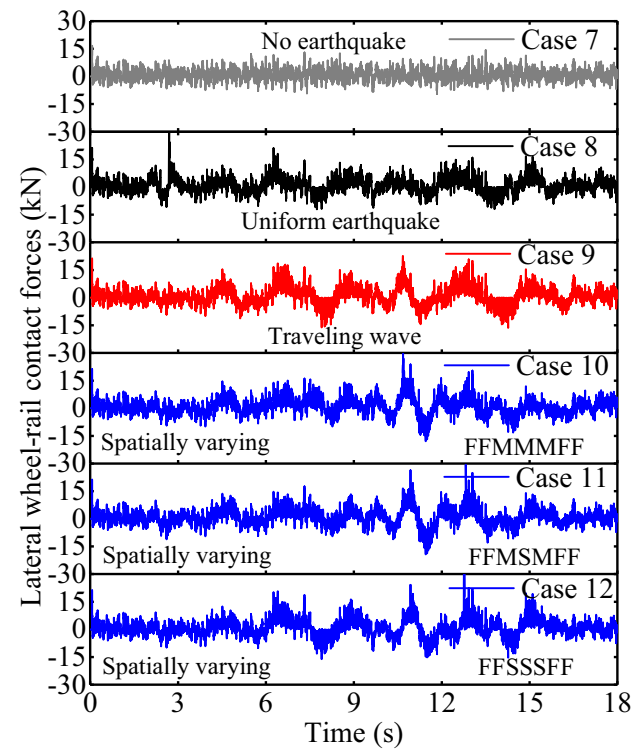

(b)

Fig. 14 Time histories of the lateral wheel-rail contact forces of the first left wheel: a cases 1-6; b cases 7-12

deteriorates the train running safety, both under normal conditions and earthquake excitation.

When the results of cases 2 and 3 , or cases 7 and 8 , are compared, differences are apparent between the responses under uniform earthquake excitation and those under traveling waves. This indicates that the traveling effect influences the responses of the train-track-bridge coupled system under earthquake to some extent. Furthermore, as shown in Fig. 15, the overall trends of the lateral wheelrail contact forces and those of the lateral car-body acceleration basically remain consistent, in both cases 2 and 3 (in cases 7 and 8, same observations can be found, but the figures are not given), and the lateral wheel-rail contact forces oscillate around the overall trend with a roughly constant amplitude. These results imply that earthquake excitations that contain varying frequency components 
Table 4 Maximum running safety indices of all cases

\begin{tabular}{llll}
\hline Case & Wheel/rail lateral force $(\mathrm{kN})$ & Derailment factor & Wheel unloading rate \\
\hline 1 & 8.85 & 0.11 & 0.29 \\
2 & 14.54 & 0.17 & 0.34 \\
3 & 17.00 & 0.24 & 0.43 \\
4 & 16.53 & 0.21 & 0.32 \\
5 & 15.00 & 0.19 & 0.35 \\
6 & 43.12 & 0.44 & 0.39 \\
7 & 14.19 & 0.25 & 0.60 \\
8 & 41.32 & 0.57 & 1.00 \\
9 & 23.61 & 0.29 & 1.00 \\
10 & 34.86 & 0.74 & 1.00 \\
11 & 33.75 & 0.31 & 1.00 \\
\end{tabular}

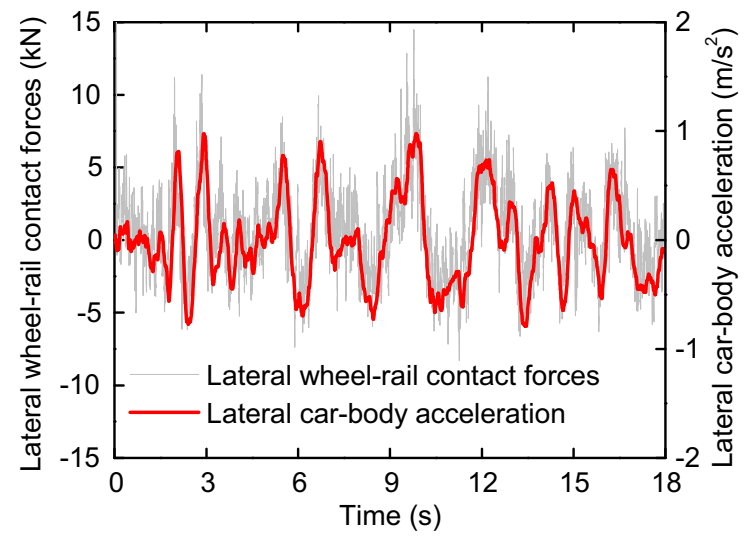

(a)

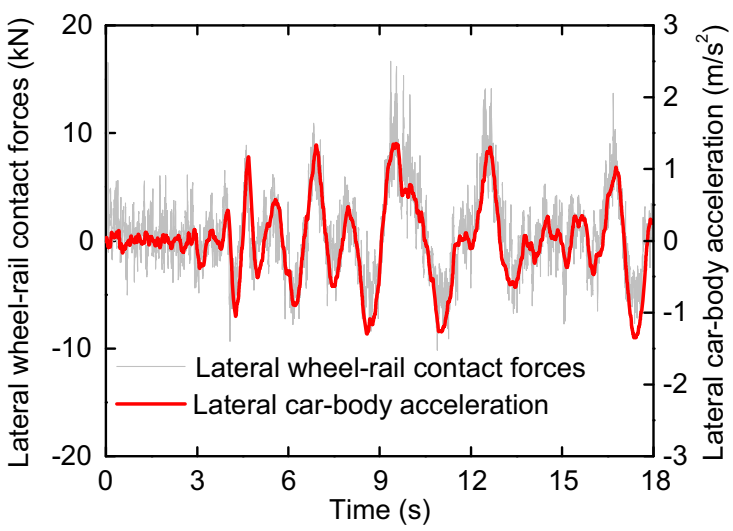

(b)

Fig. 15 Comparison between the lateral wheel-rail contact forces and the lateral car-body acceleration: a case 2; b case 3

(Fig. 11) are filtered by the train-bridge system, which possesses low natural vibration frequency (Fig. 7). Thus, the lateral wheel-rail contact forces under earthquake excitation show an overall low-frequency variation trend, compared to those under the normal condition, and the lateral car-body accelerations have the same overall trend as the lateral wheel-rail contact forces.

From the frequency domain analysis, similar conclusions can be drawn. As shown in Figs. 16 and 17, the PSD of the car-body acceleration and the bridge acceleration under no earthquake excitation is closer to zero than that under earthquake excitation, which means that the influence of the lateral track irregularity on the car body and bridge is low, compared to the influence of the earthquake. However, different types of earthquake excitation mainly influence the PSD amplitude of the car body and bridge. The main vibration frequencies vary insignificantly with different earthquake excitations. This is because the longspan bridge, which has low natural vibration frequency, filters earthquake excitations that have varying frequency components. Furthermore, the vibration frequencies of the car body and the bridge under the train speed of $160 \mathrm{~km} / \mathrm{h}$ are clearly different from those under the speed of $250 \mathrm{~km} / \mathrm{h}$. Specifically, the latter are lower than the former, which may be explained as different train speeds lead to different train locations on the bridge such that the vibration characteristics of the train-bridge system change, further influencing the vibration frequencies of the car body and bridge.

By comparing the results of case 3 with those of cases 4-6, or the results of case 9 with those of cases 10-12, we can see the influences of the spatially varying ground motion on the train-track-bridge coupled system when the incoherence effect and the site-response effect are considered. The lateral wheel-rail contact forces and the corresponding derailment factors in cases 6 and 12, where the soil condition is FFSSSFF, are greater than those in cases 3-5 and cases 9-11, respectively, as shown in Table 4. 


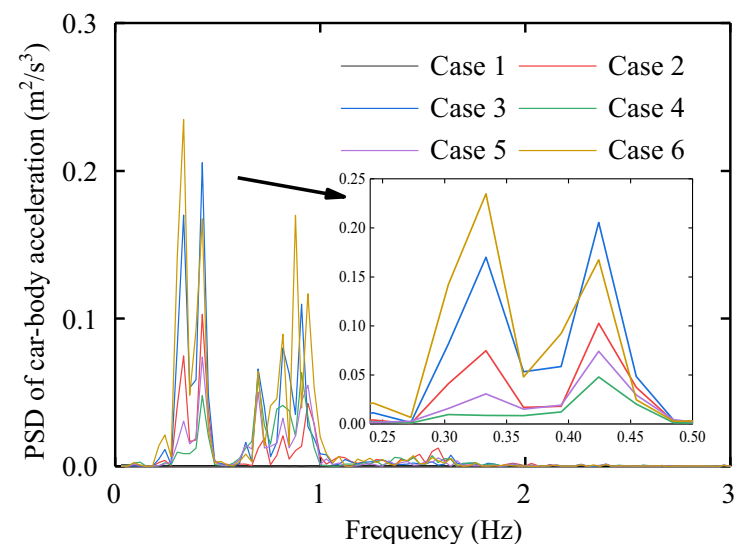

(a)

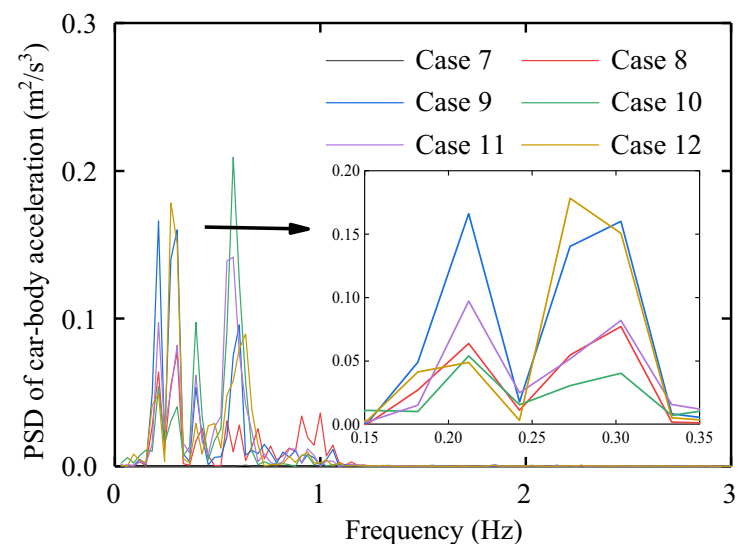

(b)

Fig. 16 PSD of the lateral car-body acceleration: a cases $1-6$; b cases 7-12

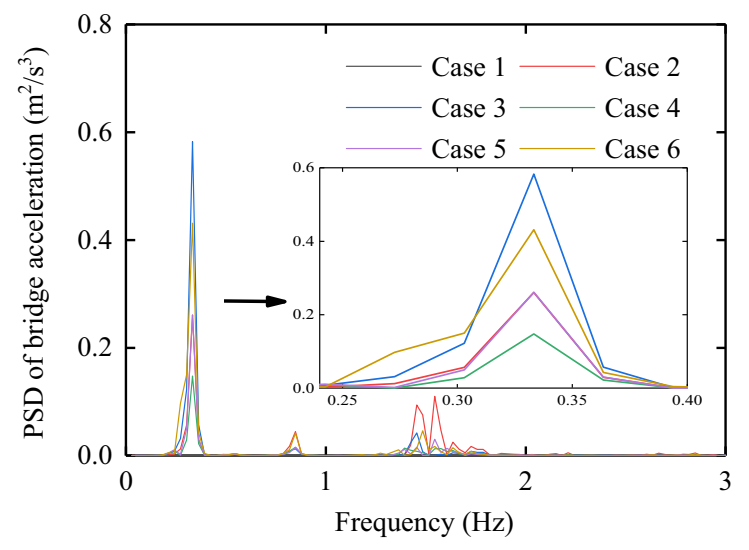

(a)

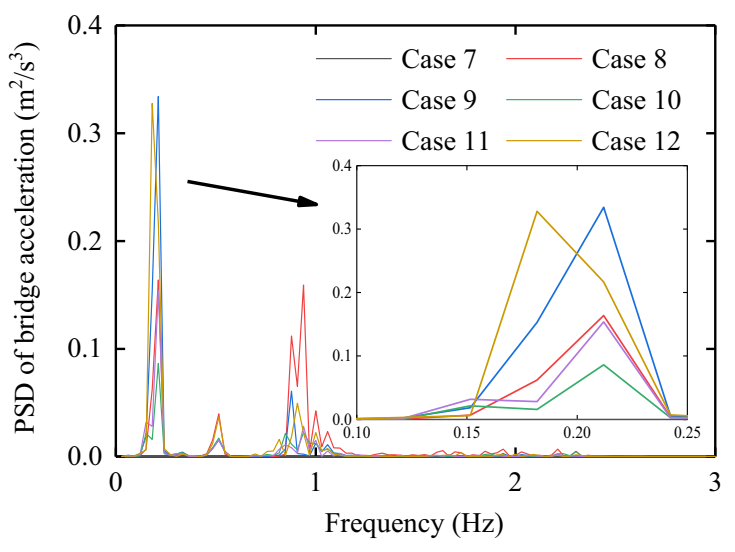

(b)

Fig. 17 PSD of the lateral bridge acceleration: a cases 1-6; $\mathbf{b}$ cases 7-12

This means that the soil conditions have effects on the train-track-bridge coupled system under earthquake, and the incoherence effect and the site-response effect should be taken into consideration in the seismic analysis of the train-track-bridge coupled system. However, some influences of the spatially varying ground motion are not consistent with different train speeds. For example, under the design speed of $160 \mathrm{~km} / \mathrm{h}$, the maxima of the lateral carbody acceleration in cases 4 and 5 (under spatially varying earthquake excitation) are lower than those in case 3 (under traveling earthquake excitation), whereas under the operation speed of $250 \mathrm{~km} / \mathrm{h}$, the maxima of the lateral carbody acceleration in cases 10 and 11 (under spatially varying earthquake excitation) are greater than those in case 9 (under traveling earthquake excitation), as shown in Fig. 12. The same observations can be identified through the running safety indices of the lateral wheel-rail contact force and the derailment factor, as shown in Table 4. In fact, one of the critical properties of earthquake is randomness; therefore, stochastic analysis is required for more comprehensive understanding of the influence of spatially varying ground motions.

\section{Conclusion}

We investigated the influences of spatially varying ground motion on the train-track-bridge coupled system. A 3D train-track-bridge model is established, in which the train is modeled by multi-body dynamics, and the track and bridge are modeled using the FEM. A 3D rolling wheelrail contact model is adopted to accurately simulate the interaction between train and bridge under earthquake excitation. The multi-time-step method previously proposed by the authors is adopted to enhance the speed of calculation. The conditioned simulation method is adopted 
to simulate spatially varying ground motions, in which not only the wave passage effect but also the incoherence effect and the site-response effect are taken into consideration. A numerical example of a train passing through a cable-stayed bridge is conducted to investigate the influence of the spatially varying ground motion. Several conclusions can be drawn:

(1) Earthquake significantly increases the responses of the train-bridge system. As a long-span bridge has a low natural vibration frequency, the earthquake excitations are significantly filtered by the trainbridge system and are harmful to the train running safety to some degree.

(2) Although showing no fixed pattern, the incoherence effect and the site-response effect, along with the traveling wave effect, influence the train-trackbridge coupled system and should be considered in seismic analyses for long-span bridges.

(3) Different train speeds lead to different train locations on the bridge and therefore vary the vibration characteristics of the train-bridge system and further influence the vibration frequencies of the bridge and car body.

As earthquake excitation is a random process, stochastic analysis is required for more comprehensive understanding of the influence of spatially varying ground motion. This will be further studied in our future work.

Acknowledgements This work was supported by the National Natural Science Foundation of China (Grant No. 51678576); the National Key R\&D Program of China (Grant No. 2017YFB1201204); China Railway Corporation R\&D Project (Grant No. 2015G001-G); and the Fundamental Research Funds for the Central Universities of Central South University (Grant No. 2018zzts031).

Open Access This article is licensed under a Creative Commons Attribution 4.0 International License, which permits use, sharing, adaptation, distribution and reproduction in any medium or format, as long as you give appropriate credit to the original author(s) and the source, provide a link to the Creative Commons licence, and indicate if changes were made. The images or other third party material in this article are included in the article's Creative Commons licence, unless indicated otherwise in a credit line to the material. If material is not included in the article's Creative Commons licence and your intended use is not permitted by statutory regulation or exceeds the permitted use, you will need to obtain permission directly from the copyright holder. To view a copy of this licence, visit http://creativecommons. org/licenses/by/4.0/.

\section{References}

1. Zhai WM, Han ZL, Chen ZW, Ling L, Zhu SY (2019) Traintrack-bridge dynamic interaction: a state-of-the-art review. Veh Syst Dyn 57(7):984-1027
2. Arvidsson T, Andersson A, Karoumi R (2019) Train running safety on non-ballasted bridges. Int J Rail Transp 7(1):1-22

3. Zhai W-M (2020) Vehicle-track coupled dynamics: theory and applications. Springer, Singapore. https://doi.org/10.1007/987981-32-9283-3

4. Fujino Y, Siringoringo D (2013) Vibration mechanisms and controls of long-span bridges: a review. Struct Eng Int 23(3):248-268

5. Asgari B, Osman SA, Adnan A (2013) Three-dimensional finite element modelling of long-span cable-stayed bridges. IES J Part A Civ Struct Eng 6(4):258-269

6. Zhong J, Jeon J-S, Ren W-X (2018) Risk assessment for a longspan cable-stayed bridge subjected to multiple support excitations. Eng Struct 176:220-230

7. Dumanogluid A, Soyluk K (2003) A stochastic analysis of long span structures subjected to spatially varying ground motions including the site-response effect. Eng Struct 25(10):1301-1310

8. Hoseini SS, Ghanbari A, Davoodi M (2017) Evaluation of long bridges dynamic responses under the effect of spatially varying earthquake ground motion. Bridge Struct 13(1):25-42

9. Zhang YH, Li QS, Lin JH, Williams FW (2009) Random vibration analysis of long-span structures subjected to spatially varying ground motions. Soil Dyn Earthq Eng 29(4):620-629

10. Sgambi L, Garavaglia E, Basso N, Bontempi F (2014) Monte Carlo simulation for seismic analysis of a long span suspension bridge. Eng Struct 78:100-111

11. Mu D, Gwon S-G, Choi D-H (2016) Dynamic responses of a cable-stayed bridge under a high speed train with random track irregularities and a vertical seismic load. Int $\mathrm{J}$ Steel Struct 16(4):1339-1354

12. Zhang N, Xia H, De Roeck G (2010) Dynamic analysis of a trainbridge system under multi-support seismic excitations. J Mech Sci Technol 24(11):2181-2188. https://doi.org/10.1007/s12206010-0812-7

13. Frýba L, Yau J-D (2009) Suspended bridges subjected to moving loads and support motions due to earthquake. J Sound Vib 319(1):218-227

14. Xia H, Han Y, Zhang N, Guo WW (2006) Dynamic analysis of train-bridge system subjected to non-uniform seismic excitations. Earthq Eng Struct Dyn 35(12):1563-1579

15. Zeng ZP, Zhao YG, Xu WT, Yu ZW, Chen LK, Lou P (2015) Random vibration analysis of train-bridge under track irregularities and traveling seismic waves using train-slab track-bridge interaction model. J Sound Vib 342:22-43

16. Zhong J, Jeon J-S, Yuan WC, DesRoches R (2017) Impact of spatial variability parameters on seismic fragilities of a cablestayed bridge subjected to differential support motions. J Bridge Eng 22(6):04017013. https://doi.org/10.1061/(asce)be.19435592.0001046

17. Konakli A (2011) Stochastic dynamic analysis of bridges subjected to spatially varying ground motions. Dissertation, UC Berkeley

18. Kiureghian A-D (1996) A coherency model for spatially varying ground motions. Earthq Eng Struct Dyn 25(1):99-111

19. Gao YF, Wu YX, Li DY, Liu HL, Zhang N (2012) An improved approximation for the spectral representation method in the simulation of spatially varying ground motions. Probab Eng Mech 29:7-15

20. Cacciola P, Deodatis G (2011) A method for generating fully non-stationary and spectrum-compatible ground motion vector processes. Soil Dyn Earthq Eng 31(3):351-360

21. Bi K, Hao H (2012) Modelling and simulation of spatially varying earthquake ground motions at sites with varying conditions. Probab Eng Mech 29:92-104 
22. Heredia-Zavoni E, Santa-Cruz S (2000) Conditional simulation of a class of nonstationary space-time random fields. J Eng Mech 126(4):398-404

23. Kiureghian A-D, Neuenhofer A (1992) Response spectrum method for multi-support seismic excitations. Earthq Eng Struct Dyn 21(8):713-740

24. Liao S, Zerva A (2006) Physically compliant, conditionally simulated spatially variable seismic ground motions for performance-based design. Earthq Eng Struct Dyn 35(7):891-919

25. Zhu ZH, Gong W, Wang LD, Harik IE, Bai Y (2017) A hybrid solution for studying vibrations of coupled train-track-bridge system. Adv Struct Eng 20(11):1369433217691775. https://doi. org/10.1177/1369433217691775

26. Zhu ZH, Gong W, Wang LD, Li Q, Bai Y, Yu ZW, Harik IE (2018) An efficient multi-time-step method for train-track-bridge interaction. Comput Struct 196:36-48

27. Zhu ZH, Gong W, Wang LD, Bai Y, Yu ZW, Zhang L (2019) Efficient assessment of 3D train-track-bridge interaction combining multi-time-step method and moving track technique. Eng Struct 183:290-302

28. Chatfield C (2003) The analysis of time series: an introduction. Chapman and Hall/CRC, Boca Raton

29. Şafak E (1995) Discrete-time analysis of seismic site amplification. J Eng Mech 121(7):801-809

30. Chen G, Zhai WM (2004) A new wheel/rail spatially dynamic coupling model and its verification. Veh Syst Dyn 41(4):301-322
31. Zhai WM, Xia H, Cai CB, Gao MM, Li XZ, Guo XR, Zhang N, Wang KY (2013) High-speed train-track-bridge dynamic interactions - part I: theoretical model and numerical simulation. Int J Rail Transp 1(1-2):3-24

32. Liu K, Zhang N, Xia H, De Roeck G (2014) A comparison of different solution algorithms for the numerical analysis of vehicle-bridge interaction. Int J Struct Stab Dyn 14(02):1350065. https://doi.org/10.1142/S021945541350065X

33. Zhang W, Cai CS, Pan F (2013) Finite element modeling of bridges with equivalent orthotropic material method for multiscale dynamic loads. Eng Struct 54:82-93

34. Ernst H-J (1965) Der E-Modul von Seilen unter berucksichtigung des Durchhanges. Der Bauingenieur 40(2):52-55

35. Lei XY (2017) High speed railway track dynamics. Springer, Berlin. https://doi.org/10.1007/978-981-10-2039-1

36. Zhang N, Xia H (2013) Dynamic analysis of coupled vehiclebridge system based on inter-system iteration method. Comput Struct 114-115:26-34

37. Soyluk K, Dumanoglu A (2004) Spatial variability effects of ground motions on cable-stayed bridges. Soil Dyn Earthq Eng 24(3):241-250

38. Rezaeian S, Der Kiureghian A (2008) A stochastic ground motion model with separable temporal and spectral nonstationarities. Earthq Eng Struct Dyn 37(13):1565-1584 